\title{
Science for profit. What are the ethical implications of bioprospecting in the Arctic and Antarctica?
}

\author{
David K. Leary ${ }^{1, *}$, David W. H. Walton ${ }^{2, * *}$ \\ ${ }^{1}$ Faculty of Law, University of New South Wales, UNSW, Sydney, New South Wales 2052, Australia \\ ${ }^{2}$ British Antarctic Survey, High Cross, Madingley Road, Cambridge CB3 0ET, UK
}

\begin{abstract}
The value of chemical compounds and their genetic sources in species from the polar regions is becoming widely recognised as a resource not yet fully exploited. Bioprospecting is a growing activity in the Arctic, where the states concerned are signatories to the Convention on Biological Diversity, providing a national framework for ownership, management and control of the activities. In the Antarctic, no such framework exists, and with increasing interest in both microbes and marine species there are concerns that uncontrolled exploitation will damage biodiversity, inhibit scientific research and data exchange, and (through disputes) undermine the authority of the Antarctic Treaty. Papers in this Theme Section highlight the ethical problems of commercialisation of science in the Antarctic for both governments and individuals, and discuss the concept of exclusive reward in a global common, leading finally to a suggestion that a new legal instrument is needed to manage Antarctic bioprospecting for the future.
\end{abstract}

KEY WORDS: Exploitation · Biodiversity $\cdot$ Antarctic Treaty System $\cdot$ Bioprospecting

\section{THE COMMERCIALISATION OF THE POLAR REGIONS}

The Arctic and Antarctica are becoming increasingly accessible to commerce and industry. In the former, technological advances and changes in the Arctic environment due to climate change have made access to the Arctic's oil and gas resources a major economic factor, now of global importance; the more recent rapid retreat of the sea ice will provide new lucrative shipping routes from Asia to Europe in due course. Existing fishing grounds in the Arctic seem set to enlarge as the ice retreats, and sea-borne tourism has been steadily growing for the last 15 yr and now brings around a million people to the Arctic each year. In Antarctica and the Southern Ocean ever increasing human activities, such as tourism and fishing, have been placing increasing pressures on one of the world's last great wilderness areas.
It is in this context that debate is slowly emerging on bioprospecting in the Arctic and Antarctica. There is now clear evidence that bioprospecting (the search for new compounds in organisms that may have industrial, pharmaceutical or other applications) is occurring in both polar regions. Developments in a diverse range of scientific disciplines - such as systematics, microbiology, ecology, evolutionary biology, physiology, biochemistry and molecular biology - now make it possible for commerce to tap the hidden potential of the extreme environments of the Arctic and Antarctica (USA National Research Council 2001).

While much of the discussion so far surrounding bioprospecting in the polar regions has focused on its nature and scale, whether it should or should not be regulated, and if so how it should be regulated, there has been little consideration of the ethical implications of bioprospecting in these regions. Bioprospecting raises a range of ethical questions globally. 
Outside the polar regions, it has been one of the most controversial issues in environmental diplomacy over recent decades because of its close connection with debates surrounding sustainable development and the so-called north-south divide; ethical arguments surrounding bioprospecting have often centered on the perceived exploitation of the genetic resources of the mega-diverse tropical countries of the developing south, primarily by large companies from the developed north. Issues surrounding the fairness or equity of the sharing of benefits of exploitation of genetic resources are at the core of that debate. International agreement on how to treat rights to genetic resources was negotiated in the 1992 Convention on Biological Diversity. So far, 157 countries have acceded to or ratified the convention, making it one of the most widely supported international agreements. However, it is applicable only to sovereign states, so, despite the fact that almost all the Antarctic Treaty Parties have accepted the convention, its application to Antarctica presents complex legal problems (see for example discussion in Leary 2008, 2009).

The purpose of this Ethics in Science and Environmental Politics (ESEP) Theme Section (TS) was therefore to open up the debate on the ethics of bioprospecting to cover the new special problems thrown up by the polar regions. In issuing a call for papers for this TS we had hoped to consider the complex ethical issues posed by bioprospecting in the polar regions from a range of perspectives, including those of scientists, parties with commercial interests, indigenous people, policy makers and legislators.

We were keen in particular to see to what extent the ethical issues were similar in both polar regions. After all, it is possible to discern a number of similarities between bioprospecting in the Arctic and in Antarctica. These include (1) an emphasis on bioprospecting in the marine environment in both regions, (2) interest in the genetic resources of both regions for applications in human health care products (including pharmaceuticals), food technology and life sciences, (3) involvement of researchers and companies from both developed and developing countries, and (4) clear evidence of patenting of new developments in biotechnology based on or derived from Arctic and Antarctic genetic resources (Leary 2008, 2009).

There are, of course, many significant differences between the Arctic and Antarctica. Much of the Arctic is sovereign territory with relatively few areas of contested territorial claims. Contrast this with the situation in Antarctica where the unresolved sovereignty question haunts all discussions on resource issues pertaining to the region. Also, as is often noted, the Arctic is a vast ocean surrounded by land, while the Antarctic is a continent surrounded by ocean. In Antarctica, human occupation is a relatively recent phenomenon with a few permanent settlements inhabited by transient populations. In contrast, the Arctic has been home to indigenous peoples with a close kinship to land and sea for thousands of years.

Unfortunately, none of the papers we received considered ethical questions concerning bioprospecting in the Arctic in any great detail. Instead, in this TS, we publish 4 excellent papers which explore ethical issues surrounding bioprospecting in Antarctica. All of these papers focus in particular on ethical issues surrounding the nexus between science and bioprospecting in Antarctica. This, of course, is no surprise given the unique and important role science has played in the history of human endeavour in Antarctica and the fact that bioprospecting lives in a symbiotic relationship with science. Without science in Antarctica there can be no bioprospecting. Like many symbiotic relationships, bioprospecting poses many risks and challenges for science in Antarctica.

Previous negotiations on Antarctic resources have either ended in a new instrument of governance (e.g. the Convention on Antarctic Marine Living Resources) or in the banning of the activity completely, as was finally agreed for mining of Antarctica's mineral resources. In both cases, the commodity was one present in the region which would be collected/harvested and transported elsewhere for processing and consumption. The business models for fishing and minerals are well developed elsewhere in the world, and it was easy to see how they could be applied to Antarctica. In neither case would the science information gained be out of the reach of scientists.

The situation for bioprospecting is much less clear, as are the current business models. Governments are urging their scientists to develop Antarctic science to make money whilst insisting that this will not breach the freedom to undertake research and access all scientific data. There is clearly an ethical problem here if commercial development requires data to be held in confidence, or if patenting gene sequences were to restrict freedom of research. Ownership of rights is also potentially contentious. For example, if a scientist from one country collects microbial material for scientific investigation whilst being supported by the logistics of another country and after completing the work gives a sample to a scientist from a third country, who then claims patent rights and what are the obligations of that scientist to those who supported the original collection in the field? Some of these elements are discussed in detail in the papers in this TS, but we see this as only the start of this ethical debate, one which the Treaty Parties have so far managed to ignore. 


\section{OVERVIEW OF PAPERS IN THIS TS}

Alan Hemmings in his article Does bioprospecting risk moral hazard for science in the Antarctic Treaty System? explores the symbiotic relationship between science and bioprospecting in Antarctica (Hemmings 2010, this TS). He highlights how bioprospecting in Antarctica has been generated in the course of, and is largely driven by, the success of Antarctic science. This has been made possible by the 'entrenched and privileged role' (Hemmings 2010, p. 5) science has had in the international governance regime for Antarctica. But, as this author then goes on to argue, science and bioprospecting are closely linked, and science will have great difficulty in managing its dual role of providing disinterested and independent advice while also taking part in the activity for which that advice is provided. Bioprospecting therefore poses a very real moral hazard for science in Antarctica.

In a similar vein, Kevin Hughes and Paul Bridge explore the potential impacts of Antarctic bioprospecting and associated commercialisation upon Antarctic science and scientists (Hughes \& Bridge 2010, this TS). They argue that beyond the issues debated so far, such as benefit sharing and the potential environmental impacts, the effect of bioprospecting on key issues of concern to scientists - e.g. science funding, the potential for personal gain, international scientific collaboration, and interaction with industry partners - needs to be more closely scrutinised and debated within the scientific community. As they highlight (Hughes \& Bridge 2010, p. 17), 'it is conceivable that once the business world is entered with significant financial gain in prospect' the subtleties of the Antarctic Treaty and the important privileged role it ascribes to science may easily be forgotten. Scientists must be cognizant of these risks and the implications they hold for science.

Julia Jabour in Biological prospecting: the ethics of exclusive reward from Antarctic activity explores how differing views of Antarctica's status, as a global commons, the common heritage of mankind or otherwise complicates resolution of the bioprospecting issue in Antarctica (Jabour 2010, this TS). She argues that while Antarctica's unique physical attributes are what attracts 'bioprospectors' to Antarctica, the region is also unique from another perspective: it is politically and legally sui generis. Exploring the 'ethics of exclusive reward' from Antarctic bioprospecting she highlights how resolution of the bioprospecting question is closely allied to whether Antarctica is characterised as a global commons or the common heritage of mankind. She argues that the exclusive reward from bioprospecting is as legitimate as exclusive reward from fishing in the Southern Ocean, with important implications for existing international regulatory regimes.
Finally, Ann-Isabelle Guyomard considers the ethics of bioprospecting in Antarctica in light of the fundamental ethical principles which have been embedded in the Antarctic Treaty System since its inception; namely, peace, the freeze on territorial claims, freedom of scientific research, international cooperation and environmental protection in the interest of humanity as a whole (Guyomard 2010, this TS). Importantly, in her paper she seeks to address the question: 'How can bioprospecting be organised in Antarctica to match these ethical concerns without a sovereign governance structure that is predicated in ... [global legal instruments such as the Agreement on Trade-related Aspects of Intellectual Property Rights, the Convention on Biological Diversity and the United Nations Convention on the Law of the Sea]?' (Guyomard 2010, p. 31). In addressing this question she argues the case for the creation of an ad hoc Antarctic legal regime.

\section{DEBATE TO CONTINUE}

At the most recent Antarctic Treaty Consultative Meeting held in Baltimore in the USA in 2009, a record 10 information and working papers devoted solely to bioprospecting in Antarctica were presented by State Parties and other organisations. Papers were presented by Argentina (Argentina 2009), Australia and New Zealand (Australia and New Zealand 2009), Belgium (Belgium 2009), Brazil (Brazil 2009), Chile (Chile 2009), The Netherlands (Netherlands 2009), the Russian Federation (Russian Federation 2009), the Scientific Committee on Antarctic Research (SCAR 2009), Sweden (Sweden 2009), and the United Nations Environment Programme (UNEP 2009). Despite this wealth of information, no clear step forward on this issue was achieved other than deciding to keep examining the issue. It appears likely, therefore, that the ethical issues surrounding bioprospecting and the corresponding scientific, commercial, legal and policy implications they give rise to will continue to be debated for many years to come. We hope this small ESEP TS adds constructively to that debate.

Acknowledgements. We thank the contributors for their articles as well as the anonymous peer reviewers for their review of the papers and useful feedback which have helped to improve the quality of this special theme section. Thanks also to Dr. Stephanie Suhr and Penny Kuhn for their assistance and patience in producing this ESEP theme section.

\section{LITERATURE CITED}

Argentina (2009) ATCM XXX II-IP 84 Update on the activities of the Argentine Antarctic program on bioprospecting and bioremediation in Antarctica 
Australia and New Zealand (2009) ATCM XXX II-WP 18 Regulation of biological prospecting under the Antarctic Treaty System

Belgium (2009) ATCM XXX II-WP 1 The Antarctic biological prospecting database

Brazil (2009) ATCM XXX II-IP 115 Bioprospecting activities of Brazil in Antarctica: a short report following Resolution 7 (2005)

Chile (2009) ATCM XXX II -WP 49 rev. 2 Bioprospection: baselines and parameters

> Guyomard AI (2010) Ethics and bioprospecting in Antarctica. Ethics Sci Environ Polit 10:31-44

Hemmings AD (2010) Does bioprospecting risk moral hazard for science in the Antarctic Treaty System? Ethics Sci Environ Polit 10:5-12

Hughes KA, Bridge PD (2010) Potential impacts of Antarctic bioprospecting and associated commercial activities upon Antarctic science and scientists. Ethics Sci Environ Polit 10:13-18

Jabour J (2010) Biological prospecting: the ethics of exclusive reward from Antarctic activity. Ethics Sci Environ Polit 10:19-29

Leary D (2008) Bi-polar disorder? Is bioprospecting an

Submitted: March 11, 2010; Accepted: April 8, 2010 emerging issue for the Arctic as well as for Antarctica? Review of European Community \& International Law 17(1):41-55

Leary D (2009) Bioprospecting in Antarctica and the Arctic. Common challenges? Yearbook of Polar Law 1: 145-174

Netherlands (2009) ATCM XXX II-WP 26 A gap analysis of the Antarctic Treaty System regarding the management of biological prospecting

Russian Federation (2009) ATCM XXX II-IP 46 Microbiological monitoring of the expedition infrastructure facilities in the Antarctic

Scientific Committee on Antarctic Research (2009) ATCM XXX II- IP 65 Biological prospecting in the Antarctic: An update on the review by SCAR

Sweden (2009) ATCM XXX II -IP 70 Concepts, Terms and Definitions, including a Comparative Analysis (Biological Prospecting)

United Nations Environment Programme (UNEP) (2009) ATCM XXX II- IP 91 Biological Prospecting: an update on recent policy developments at the international level

USA National Research Council (2001) Frontiers in polar biology in the genomic era. National Research Council of the National Academies, Washington, DC

Proofs received from author(s): May 2, 2010 